\title{
El registro de los actos sancionatorios y la preclusión de la potestad disciplinaria municipal
}

\section{Relación de la Contraloría General de la República respecto de las resoluciones que afecten a funcionarios municipales}

En primer término debe destacarse que de acuerdo al principio de juridicidad, en que se sustenta nuestro ordenamiento jurídico y que consagran los artículos 6 y 7 de la Carta Fundamental, los órganos de la Administración del Estado, entre los cuales por mandato del artículo $1^{\circ}$ de la Ley 18.575 Orgánica Constitucional de Bases Generales de la Administración del Estado, se encuentran las Municipalidades, deben someter su acción a la Constitución y a las normas dictadas conforme a ella, y actúan válidamente previa investidura regular de sus integrantes, dentro de su competencia y en la forma que prescribe la ley.

Siguiendo en esta misma línea de razonamiento, cabe señalar que el artículo $2^{\circ}$ de la Ley Orgánica Constitucional de Bases Generales de la Administración del Estado, dispone que los órganos de la misma, someterán su acción a la Constitución y las leyes, debiendo actuar dentro de su competencia, no teniendo más atribuciones que las que expresamente les haya conferido el ordenamiento jurídico.

Ahora bien, este control de la legalidad por expreso mandato de la Carta Fundamental le corresponde a la Contraloría General de la República (arts. 98 y 99 C.P.R.), que lo ejerce de conformidad a las disposiciones contenidas en la Ley 10.336 sobre Organi-

* Profesor de Derecho Municipaly Derecho Urbanistico, Universidad de Chile. zación y Atribuciones de la Contraloría General de la República.

De especial interés es la normativa contenida en los arts. $6^{\circ}, 9^{\circ}$ y 19 de la Ley $10.336, y$ siendo los municipios gozan de una autonomía, de acuerdo al art. $1^{\circ}$ de la Ley 18.695, refrendada en materia de finanzas por el art. 14 del mismo cuerpo legal, no es menos 
cierto que si bien sus resoluciones se encuentran exentas del trámite de toma de razón ${ }^{1}$, deberán registrarse en el órgano contralor, cuando afecten a funcionarios municipales, y justamente para tal objeto la Contraloría General de la República, deberá llevar un registro del personal municipal en la forma y condiciones en que lo hace para el resto del sector público, debiendo las municipalidades remitir los antecedentes que el órgano contralor solicite. ${ }^{23}$

De todo lo anterior se concluye, que a la Contraloría General de la República le corresponde la Fiscalización de las Municipalidades y en lo que respecta a las resoluciones que afecten a los funcionarios municipales, le compete proceder a su registro. ${ }^{4}$

Así puede colegirse que en general al Órgano Contralor le cabe un rol fiscalizador respecto de las entidades edilicias, especialmente enfocado en el manejo de fondos, encontrándose las resoluciones municipales no afectas al trámite de toma de Razón, debiendo eso si proceder a Registrarse todas aquellas que afecten a los funcionarios municipales.

Ahora bien, de acuerdo a la Ley $18.883^{5}$ la responsabilidad administrativa de los funcionarios municipales se hace efectiva mediante sumarios, conforme al procedimiento establecido en la mencionada ley, el que concluye con el Decreto del Alcalde que absuelve o aplica la medida disciplinaria propuesta por el Fiscal.

Es precisamente el aludido decreto alcaldicio el que debe ser registrado por la Contraloría General de la República.

II

\section{Alcance del registro que practica la Contraloría General de la República respecto de las resoluciones dictadas en sumarios administrativos en contra de funcionarios municipales}

Ya hemos visto que la Contraloría General de la República, ejerce el control de legalidad sobre los municipios y que en lo referente a las resoluciones que afecten a funcionarios municipales, estas deben registrarse.

¿Qué alcance tiene este registro? ¿La Contraloría solo debe limitarse a registrar la resolución sin poder emitir observaciones sobre el particular?

Algunos piensan que dado el principio autonómico que inspira el régimen municipal, al Órgano Contralor solo le cabría cumplir con el mero registro, y que cualquier ob-

Art. 53 Ley 18.695.

Art. 53 inciso $2^{\circ}$ Ley 18.695

El texto refundido coordinado, sistematizado y actualizado de la Ley 18.695 Orgánica Constitucional de Municipalidades, fue fijado por el Decreto con Fuerza de Ley No 1-9.704 publicado en el Diario Oficial de 3-5-2002.

Ver en Derecho Municipal chileno. Edit. Jurídica. 2a Edición año 2007, José Fernández Richard, pág. 193 fallo, C. Suprema ingreso 723-98 relativo a instrucción de municipio administrativo.

Art. 124 Ley 18.883 
servación que efectúe sobre la resolución registrada, carecería de sustento jurídico.

Esta no es nuestra opinión, ya que estimamos que conforme a lo dispuesto en los arts. 51, 52 y 53 de la Ley 18.695 Orgánica Constitucional de Municipalidades, a la Contraloría le compete la fiscalización de los municipios, pudiendo emitir dictámenes jurídicos sobre todas las materias sujetas a su control

De tal modo que el órgano contralor junto con dar cumplimiento a su deber de registrar la resolución que afecte a un funcionario municipal, puede válidamente efectuar las observaciones que tal resolución le merezca. Lo que le está vedado a la Contraloría es negarse o abstenerse de registrar el decreto alcaldicio en cuestión, lo que no impide que pueda conjuntamente con practicar el registro, emitir las observaciones que dicha resolución le merezca. ${ }^{6}$

\section{III}

\section{Situación del Alcalde que recibe observaciones de la Contraloría General de la República, en relación a un decreto registrado por dicho órgano contralor}

Normalmente las observaciones que efectúa la Contraloría General de la República, al registrar un Decreto Alcaldicio dictado en un sumario que afecte a un funcionario municipal, deben ser tomadas en cuenta por el Alcalde, sirviéndole de guía para actuaciones futuras.

Puede ocurrir que la resolución registrada imponga una sanción distinta a la que correspondería adoptar, de acuerdo al Estatuto Administrativo de los Funcionarios Municipales. ${ }^{7}$

En el evento antes aludido el Órgano Contralor puede hacer presente a la autoridad edilicia que dicte un decreto fundado en el que exprese las razones o motivos que influyen en tal decisión. Lo anterior tiene su respaldo en la Ley Orgánica Constitucional de la Contraloría General, ya que su artículo 133 bis dispone que la resolución que impone una sanción distinta de la correspondiente a los funcionarios municipales, debe efectuarse mediante una resolución fundada. Nos estamos poniendo en la hipótesis en que la Ley impone una medida disciplinaria determinada para una situación que ella contempla, y en que el Alcalde establece una medida diversa.

En tal caso al Alcalde le corresponde acatar lo observado por la Contraloría ya que si bien la potestad disciplinaria se encuentra en él radicada, conforme a lo previsto en el inciso primero del artículo 56 de la Ley 18.695 en relación con el artículo 63 letra c) d) y j) del mismo cuerpo legal, no lo es menos que tiene que fundamentar porque ha impuesto una sanción distinta a la prevista por la ley.

Esta actitud la Contraloría la ha sustentado en forma permanente. Como ejemplo citamos dictámenes № 53.409 de 26 de Noviembre del 2003 $\otimes$ Dictamen No 60.604 de 7 Diciembre 2004, etc.

Ley 18.883. D. Oficial 29-12-1989 
Lo que el Alcalde no puede hacer es modificar la sanción disciplinaria que impuso en el Decreto que fue registrado en el Órgano Contralor, por las razones que veremos más adelante.

\section{IV \\ Registro de acto sancionatorio determina preclusión de la potestad disciplinaria municipal}

Nadie discute que la potestad disciplinaria sobre los funcionarios municipales le corresponde al Alcalde de la respectiva Municipalidad y que tal potestad, la ejerce a través de informaciones sumarias o mediante sumarios administrativos que terminan con un decreto alcaldicio que absuelve al funcionario o bien le impone una medida disciplinaria determinada.

Ahora bien, el Alcalde de acuerdo al mérito de los autos sumariales puede imponer una sanción menor a la establecida por la Ley para una situación específica, pero si así lo hace, debe efectuarlo mediante una resolución fundada en que explique los motivos que tuvo para proceder en el sentido en que lo hizo. ${ }^{8}$

Al dictar el Alcalde el decreto sancionatorio, y al ser este motivo de registro por parte del Órgano Contralor, se ha puesto término a todo un procedimiento reglado por el Estatuto Administrativo de los Funcionarios Municipales, en la Ley 18.883, y en tal sentido puede afirmarse que el Alcalde ha agotado su potestad disciplinaria en el caso específico de que se trata. A nuestro parecer en esta situación se produce la preclusión de la potestad disciplinaria municipal. Estimamos que el Alcalde actuaría contrario a Derecho, si al tenor de las observaciones de la Contraloría, dejara sin efecto el decreto sancionatorio y dictara un nuevo decreto imponiendo una sanción diversa a la primitiva, ya registrada.

Sostenemos lo anterior, en razón de que al tenor de la Ley 18.883, el sumario administrativo para perseguir la responsabilidad funcionaria de los empleados municipales concluye con el decreto alcaldicio que absuelve o sanciona con una medida disciplinaria, procedimiento que se complementa con el trámite de registro en la Contraloría General de la República.

Es interesante destacar que un fallo de la Iltma. Corte de Apelaciones de Santiago de una data más o menos reciente recoge esta misma doctrina, ${ }^{9}{ }^{10}$ al acoger un recurso de protección, respecto del nuevo decreto dictado por un Alcalde, que imponía una sanción distinta a la que ya había sido registrada por la Contraloría General de la

\footnotetext{
Ver Gaceta Jurídica año 2005 abril No 298 Pág. 82 y siguientes.

Recurso de protección Rol 8.898-2004 Corte de Apelaciones de Santiago, sentencia de 14 Abril del 2005.

Gaceta Jurídica ańo 2005 Abril No 298 págs. 82 y siguientes.
} 
República, estimando que en tal evento se vulneraron las garantías constitucionales de los números 3 inciso $4^{\circ}$ y 24 del artículo 19 de la Carta Fundamental.

En suma, estimamos que con la dictación del Decreto Alcaldicio que absuelve o impone una medida disciplinaria y su subsiguiente registro en la Contraloría General de la República, se ha puesto término al procedimiento sumarial dispuesto en la Ley 18.883, precluyendo así la potestad disciplinaria municipal, que le incumbía al Alcalde en ese caso concreto. 